\title{
The view of medical students on the anatomy course given by distance education during Covid-19 pandemic
}

\author{
Ozan Turamanlar (D), Hilal Güzel (D) \\ Department of Anatomy, Faculty of Medicine, Afyonkarahisar Health Sciences University, Afyonkarahisar, Turkey
}

\begin{abstract}
Objectives: The Covid-19 pandemic has caused serious problems all around the world. Face-to-face education in universities had shifted to the distance learning including medical schools. Our aim in this study was to understand the problems faced by medical students during pandemic period, as well as to determine the possible benefits of distance learning through a web-based questionnaire system, and to compare it with face-to-face learning.

Methods: This cross-sectional study was conducted with a structured internet-based questionnaire. The sample of the study consists of 335 medical students who volunteered to participate in the study. The students took the anatomy course remotely during the Covid-19 and had access to the internet-based questionnaire.

Results: Medical students thought that the online theoretical and practical anatomy lectures were not sufficient for their medical profession. Most of the students were opposed to providing practical lectures in the form of distance learning. Students were not satisfied with the anatomy lectures they took during this period.
\end{abstract}

Conclusion: This study showed that the medical students did not look positively towards distance learning. Further studies should be conducted to assess the effectiveness of various distance learning strategies for better anatomy education.

Keywords: anatomy; Covid-19; distance education; medical students

Anatomy 2020;14(3):202-209 (2020 Turkish Society of Anatomy and Clinical Anatomy (TSACA)

\section{Introduction}

In December 2019, a large number of pneumonia with unknown cause was detected in a seafood market in Wuhan, China. Following the rapidly increasing number of cases, the World Health Organization (WHO) announced in January 2020 that the reason for these complaints in patients is a new type of coronavirus (SARS$\mathrm{CoV}-19)$. An international emergency has been declared due to the spread of the disease first to all regions of China and then to other countries. In February 2020, in the report published by $\mathrm{WHO}$, the official name of the new disease was announced as "Coronavirus Disease 2019" and the abbreviation was named as "Covid-19". As Covid-19 spread to many countries in a very short time and became a global epidemic, on March 11th, 2020, WHO declared the epidemic as a "pandemic" and asked all countries to take serious measures. ${ }^{[1]}$
The disease has started to spread immediately all over the world since March. The first case in Turkey was detected on March 11, 2020 and following the first case, number of the cases had rapidly increased. After detection of the first case, the Turkish Government has taken various precautions to fight against the pandemic. The Council of Higher Education (CoHE) suspended face-toface education in all universities during the pandemic period. In this context, it was announced that distance education at universities will be provided with digital facilities as of March 23th, 2020. ${ }^{[2,3]}$

Distance education (including technology-assisted learning that includes online, offline or both) is defined as the use of computer technology to provide education. ${ }^{[4]}$ Although its importance increases today with the pandemic, distance education has a history spanning almost two centuries. E-learning, web-based learning, computer- 
based learning, online learning, internet-based learning and distance learning are widely used interchangeably. These terms represent concepts with very small consequential differences. ${ }^{[5,6]}$

Before the pandemic, higher education and secondary education institutions had very limited online education programs in developed and developing countries. Even though education is not provided directly online, applications such as sharing lecture notes, homework tracking, attendance schedule, and education-training program calendar sharing can also be included in online education. ${ }^{[7}$ With its developing and still developing technology, distance education projects have started to be put into service with virtual reality. Due to the high quality and realism of the content of distance education projects, the technological equivalent of experiential education today is defined as virtual reality and connected technologies. ${ }^{[8]}$

Distance education gives medical students the flexibility and option to do their own self-learning at home at times that suit them. It allows medical students to control how much time they spend on any subject. This not only prevents overloading of information, but also allows them to spend more time on issues they find difficult. ${ }^{[9]}$ Distance education is one of the newest way of teaching supported by digital technologies. Using new multimedia technologies and the internet to develop and collaborate the quality of learning by facilitating access to different kind of resources and services. ${ }^{[10]}$

Considering how dynamic medical education and medical practices are, various studies have been conducted on how to deliver medical education in the most efficient way. ${ }^{[11]}$ Similar to these studies, different education models are adopted and implemented in medical schools around the world. ${ }^{[12]}$ The aim of medical education is to train qualified physicians with full theoretical knowledge for the needs of the society. Anatomy is considered the basis of the medical sciences, which physicians acquire basic knowledge to practise their professions. ${ }^{[13]}$ Anatomy is the oldest branch of medicine that investigates the normal shape and structure of the human body, the organs that compose the body, and the structural and functional relationships between these organs. ${ }^{[11]}$ Anatomy knowledge has a very important place in medical education. In some specialties such as orthopedics, radiology, general surgery and neurosurgery, good knowledge of anatomy is essential for both correct diagnosis and treatment. ${ }^{[12]}$ It has become important to evaluate the efficiency and effectiveness of medical education based on data. In particular, obtaining the opinions and thoughts of students about medical education is a method that is widely used in directing education. ${ }^{[14]}$ In addition to measuring students' learning and progress, evaluating their satisfaction during learning experiences is one of the requirements of student-centered education. ${ }^{[15]}$

It is crucial to get direct feedback from medical students in determining the difficulties, deficiencies or possible benefits that occurred during the transformation of a model planned for face-to-face learning into distance education. By evaluating student feedbacks and developing and improving the distance learning delivery model, it can enable the crisis to be turned into opportunities. ${ }^{[16]}$

With the decision of CoHE, Afyonkarahisar Health Sciences University, Faculty of Medicine had given the remaining course of the spring term as online education. Within the curriculum of the medical faculty, locomotor system anatomy course is given in the first year, and circulatory, respiratory, digestive, nervous, urinary and genital system anatomy courses are given in the second year. The aim of the present study was to understand the problems faced by 1 st and 2nd grade medical students during online anatomy course, as well as to determine the possible benefits of online education through a web-based questionnaire, and to compare it with face-to-face learning.We also aimed to evaluate the classes individually to see if this had anything to do with different anatomy topics.

\section{Materials and Methods}

This cross-sectional study was conducted in September 2020 with a structured web-based student feedback questionnaire. The sample of the study consists of 335 medical students who had access to the web-based questionnaire, volunteered to participate in the study, and took the both anatomy theoretical and practical lectures online during the Covid-19 pandemic period.

Two forms were used in the study, namely "student information form" and "web-based student feedback questionnaire". The categories in the questionnaire were determined as the evaluation of the anatomy theoretical and anatomy practical lectures taught by distance learning. The level of agreement with the expressions was graded from 1 to 5 with Likert type scaling as; " $1=$ completely disagree", "2=disagree", " $3=$ no idea", "4=agree", " $5=$ completely agree" (Appendix 1).

The 12-question questionnaire form was prepared and delivered to volunteers using the "Google Forms" application (Google Inc., Mountain View, CA, USA) sharing the link through the participants' email addresses. The survey was conducted entirely on a voluntary basis, and students who did not want to participate in the survey were not included in the study. In order to increase the reliability of the feedback, it was stated that 
it was not necessary to write names to the students who filled out the questionnaire. The possible effect of exam anxiety on students was also considered, and the questionnaire was conducted after the exam period was over.

During the pandemic period, online anatomy theoretical lectures were given both synchronously and asynchronously. All anatomy lectures were conducted using the university's own internet-based system (https://mergen.btk.gov.tr/). To facilitate the online education, the slides were shared with all of the students. Videos of anatomical models explained by research assistants separately for each practical classes were shared with the students over the internet.

The questionnaire included questions that evaluate students' feedback about the online anatomy education model. The students were asked about their opinions on the statements given about the online theoretical and practical anatomy lectures. Finally, their opinions about whether they want to continue online education after the pandemic period was also asked and evaluated.

Data were analyzed using Statistical Program for Social Science (SPSS) version 20.0 (IBM Corp., Armonk; NY, USA). Categorical data were expressed as numbers and percentages. A $\mathrm{p}<0.05$ was considered as statistically significant. Pearson's chi-square $\left(\chi^{2}\right)$ test of significance was used in order to make comparison between 1st grade versus 2 nd grade medical students answers. The actual counts from the sample data were compared with the expected counts, given the null hypothesis of no relationship.

\section{Results}

Totally, 335 medical students participated the survey. There were 211 1st grade and 124 2nd grade students among the respondents. The distribution of the students according to their gender and grades is shown in Table $\mathbf{1}$. The majority of the students attended the anatomy theoretical and practical lectures in distance learning (Table 2).
Table 1

Distribution of students by gender and grade $(n=335)$.

\begin{tabular}{lcc} 
& $\begin{array}{c}\text { 1st grade } \\
\mathbf{n}(\%)\end{array}$ & $\begin{array}{c}\text { 2nd grade } \\
\mathbf{n}(\%)\end{array}$ \\
\hline Theoretical & $202(95.7 \%)$ & $108(87.1 \%)$ \\
\hline Practical & $186(88.6 \%)$ & $114(91.9 \%)$ \\
\hline
\end{tabular}

Table 2

Students' participation in anatomy theoretical and practical lectures $(n=335)$

\begin{tabular}{lcc} 
& $\begin{array}{c}\text { 1st grade } \\
\mathbf{n}(\%)\end{array}$ & $\begin{array}{c}\text { 2nd grade } \\
\mathbf{n}(\%)\end{array}$ \\
\hline Females & $134(63.5 \%)$ & $72(58.1 \%)$ \\
\hline Males & $77(36.5 \%)$ & $52(41.9 \%)$ \\
\hline Total & 211 & 124 \\
\hline
\end{tabular}

The answers given by the students to the statements in the questionnaire are shown in separate tables as theoretical and practical lectures (Tables 3 and 4).

$61 \%$ of respondents "completely disagreed" or "disagreed" to the statement "I think that the online anatomy theoretical lectures I have taken during the pandemic period are sufficient for my medical profession", while $26 \%$ "completely agreed" or "agreed". On the other hand, $74 \%$ of the students answered as "completely disagree" or "disagree" to the statement "I think that the online anatomy practical lectures I have taken during the pandemic period will be sufficient for my medical profession", while $14 \%$ of the students as "completely agree" or "agree". In both cases, $10 \%$ of the students had no idea. In general, most of the students thought that the both online theoretical and practical anatomy lectures they take during the pandemic process will not be sufficient for their future medical profession.

While $28 \%$ of the students answered as "completely disagree" or "disagree" to the statement "I think that the

Table 3

Students' responses to the statements about anatomy practical lectures.

\begin{tabular}{lccccc} 
& Completely disagree & Disagree & No idea & Agree & Completely agree \\
\hline Statement 2 & $\% 48$ & $\% 26$ & $\% 10$ & $\% 8$ & $\% 6$ \\
\hline Statement 4 & $\% 35$ & $\% 33$ & $\% 14$ & $\% 10$ & $\% 6$ \\
\hline Statement 8 & $\% 6$ & $\% 5$ & $\% 7$ & $\% 28$ & $\% 50$ \\
\hline Statement 9 & $\% 7$ & $\% 5$ & $\% 10$ & $\% 25$ & $\% 51$ \\
\hline Statement 10 & $\% 12$ & $\% 15$ & $\% 34$ & $\% 19$ \\
\hline
\end{tabular}


Table 4

Students' responses to the statements about anatomy theoretical lectures.

\begin{tabular}{lccccc} 
& Completely disagree & Disagree & No idea & Agree & Completely agree \\
\hline Statement 1 & $\% 38$ & $\% 23$ & $\% 10$ & $\% 18$ & $\% 8$ \\
\hline Statement 3 & $\% 28$ & $\% 24$ & $\% 15$ & $\% 23$ & $\% 13$ \\
\hline Statement 5 & $\% 35$ & $\% 21$ & $\% 15$ & $\% 13$ & $\% 15$ \\
\hline Statement 6 & $\% 21$ & $\% 17$ & $\% 16$ & $\% 30$ & $\% 14$ \\
\hline Statement 7 & $\% 5$ & $\% 12$ & $\% 21$ & $\% 34$ \\
\hline
\end{tabular}

anatomy theoretical lectures should be online but anatomy practical lectures should be in the laboratory environment in the future", $46 \%$ of the students responded as "completely agree" or "agree". However, $21 \%$ of them had no idea. Approximately half of the students thought positively towards online theoretical lectures but they prefer practical lectures to be face-to-face in the laboratory.

In terms of the future education period, $61 \%$ of the students "completely disagreed" or "disagreed" to the statement "I think that the anatomy course should be given both theoretically and practically online", while $18 \%$ of them thought exactly the opposite. And, $16 \%$ of them had no idea. The majority of students opposed to online anatomy practical lectures.

The comparison of answers of 1 st and 2 nd grade students are shown in Table 5 . The 2 nd grade students found the theoretical lecture materials more inadequate compared to 1st grade students (statement 3) ( $\mathrm{p}=0.006)$. In terms of listening to the recorded lectures again (statement 6), 1st grade students think more positively about distance learning compared to 2 nd grade students $(\mathrm{p}=0.008)$.

\section{Discussion}

The Covid-19 pandemic had caused serious problems all around the world. During the Covid-19 pandemic period, face-to-face learning at universities was suspended as of March 2020 and the online education process was rapidly switched to prevent interruption of the education and training process. After the health system, the education system was affected by the lifestyle changes experienced in this extraordinary period and it forced academics to use technological fascilities. There is no doubt that medical students are also living through extraordinary times and there has been a crucial change in their teaching methods of anatomy.

Anatomy necessitates a three-dimensional comprehension of the subjects. Therefore, use of new technologies in anatomy education still remains challenging and play an important role in the future of anatomy education.
Traditional approaches such as cadaver dissection allow direct assessment of the shape and spatial relationships between adjancent anatomical structures. In order for new technologies to be successfully integrated into the anatomical curriculum, such technologies must have a comprehensive understanding of the three-dimensional nature of anatomy and body structures. ${ }^{[17]}$ It is important how the sudden change in the education system affects both medical student performance and satisfaction and future of anatomy education. For anatomy education in medical schools, these decisions were more important in that they disrupted access to cadaver resources and anatomical models. Delivering anatomy education through online, if only for a short period, effects both anatomists and medical students. $^{[18]}$

Opinions about online education are not only a matter of discussion specific to the pandemic process, and but had been focus of interest in previous years as well. The positive aspects of distance education that have been reported include; not having space and time limitations in education, providing equal opportunities for everyone, using the opportunities of technological devices, eliminating the age limit in education, ease of accessing international education opportunities, the opportunity to learn at their own pace and the student's self-responsibility in learning. ${ }^{[19]}$

Although online education has many advantages, it also has some limitations. For example, restriction of socialization, reduced effectiveness of the courses that require practice, decreased interest and motivation, difficulty in access to technological devices or problems in internet connection. ${ }^{[20]}$

Different education models are adopted and implemented in medical faculties all over the world. The classical education approach that has been going on for years in medical faculties leaves its place to integrated, interactive and active applications. In addition, thanks to the developing technology, more active applications such as online education have emerged in recent years. ${ }^{[21,2]}$ Anatomy a visual discipline, is given to students of 1 st and 2 nd year under the basic sciences in medical faculties. The effec- 
Table 5

The responses of 1st and 2 nd grade students to the statements separately. Pearson's chi-square $\left(\chi^{2}\right)$ test of significance was used in order to compare proportions between 1st grade versus 2 nd grade medical students answers. Actual counts from the sample data were compared with expected counts, given the null hypothesis of no relationship.

\begin{tabular}{|c|c|c|c|c|c|c|c|c|c|}
\hline Sta & ment & & Completely disagree & Disagree & No idea & Agree & Completely agree & df & p-value \\
\hline \multirow[t]{4}{*}{1.} & 1st grade & count & 79 & 44 & 20 & 44 & 24 & \multirow{4}{*}{4} & \multirow{4}{*}{0.063} \\
\hline & & expected count & 80.6 & 50.4 & 22.0 & 39.7 & 18.3 & & \\
\hline & \multirow[t]{2}{*}{2 nd grade } & count & 49 & 36 & 15 & 19 & 5 & & \\
\hline & & expected count & 47.4 & 29.6 & 13.0 & 23.3 & 10.7 & & \\
\hline \multirow[t]{4}{*}{2.} & \multirow[t]{2}{*}{ 1st grade } & count & 103 & 48 & 21 & 19 & 16 & \multirow{4}{*}{4} & \multirow{4}{*}{0.209} \\
\hline & & expected count & 99.4 & 55.7 & 21.3 & 18.1 & 12.5 & & \\
\hline & \multirow[t]{2}{*}{ 2nd grade } & count & 56 & 41 & 13 & 10 & 4 & & \\
\hline & & expected count & 59.6 & 33.3 & 12.7 & 10.9 & 7.5 & & \\
\hline \multirow[t]{4}{*}{3.} & \multirow[t]{2}{*}{ 1st grade } & count & 62 & 46 & 24 & 57 & 21 & \multirow{4}{*}{4} & \multirow{4}{*}{$0.006^{*}$} \\
\hline & & expected count & 60.4 & 52.2 & 32.1 & 49.0 & 16.3 & & \\
\hline & \multirow[t]{2}{*}{ 2nd grade } & count & 34 & 37 & 27 & 21 & 5 & & \\
\hline & & expected count & 35.6 & 30.8 & 18.9 & 29.0 & 9.7 & & \\
\hline \multirow[t]{4}{*}{4.} & \multirow[t]{2}{*}{ 1st grade } & count & 79 & 58 & 28 & 25 & 17 & \multirow{4}{*}{4} & \multirow{4}{*}{0.031 * } \\
\hline & & expected count & 73.2 & 69.4 & 29.4 & 21.9 & 13.1 & & \\
\hline & \multirow[t]{2}{*}{ 2nd grade } & count & 38 & 53 & 19 & 10 & 4 & & \\
\hline & & expected count & 43.8 & 41.6 & 17.6 & 13.1 & 7.9 & & \\
\hline \multirow[t]{4}{*}{5.} & 1st grade & count & 68 & 42 & 28 & 30 & 41 & & \\
\hline & & expected count & 74.1 & 44.6 & 31.4 & 27.6 & 31.4 & 1 & 0075 * \\
\hline & 2 nd grade & count & 50 & 29 & 22 & 14 & 9 & 4 & $0.0<3$ \\
\hline & & expected count & 43.9 & 26.4 & 18.6 & 16.4 & 18.6 & & \\
\hline 6. & 1st grade & count & 39 & 29 & 35 & 67 & 39 & & \\
\hline & & expected count & 43.9 & 37.0 & 34.5 & 63.4 & 30.1 & 4 & ก \\
\hline & 2nd grade & count & 31 & 30 & 20 & 34 & 9 & T & 0.000 \\
\hline & & expected count & 26.1 & 22.0 & 20.5 & 37.6 & 17.9 & & \\
\hline 7. & 1st grade & count & 14 & 21 & 50 & 46 & 78 & & \\
\hline & & expected count & 11.9 & 25.1 & 44.6 & 55.2 & 72.2 & 1 & \\
\hline & 2nd grade & count & 5 & 19 & 21 & 42 & 37 & 4 & 0.071 \\
\hline & & expected count & 7.1 & 14.9 & 26.4 & 32.8 & 42.8 & & \\
\hline 8. & 1st grade & count & 18 & 11 & 19 & 54 & 107 & & \\
\hline & & expected count & 14.5 & 12.0 & 16.4 & 60.4 & 105.8 & a & \\
\hline & 2 nd grade & count & 5 & 8 & 7 & 42 & 61 & 4 & נ5 \\
\hline & & expected count & 8.5 & 7.0 & 9.6 & 35.6 & 62.2 & & \\
\hline 9. & 1st grade & count & 17 & 9 & 25 & 52 & 106 & & \\
\hline & & expected count & 15.7 & 10.7 & 22.0 & 53.3 & 107.3 & 1 & \\
\hline & 2 nd grade & count & 8 & 8 & 10 & 33 & 65 & 4 & 0.009 \\
\hline & & expected count & 9.3 & 6.3 & 13.0 & 31.7 & 63.7 & & \\
\hline 10. & 1st grade & count & 26 & 30 & 34 & 69 & 49 & & \\
\hline & & expected count & 26.9 & 32.6 & 35.7 & 72.0 & 40.7 & & \\
\hline & 2 nd grade & count & 17 & 22 & 23 & 46 & 16 & 4 & 0.222 \\
\hline & & expected count & 16.1 & 19.4 & 21.3 & 43.0 & 24.3 & & \\
\hline 11. & 1st grade & count & 37 & 26 & 45 & 43 & 57 & & \\
\hline & & expected count & 34.5 & 25.7 & 45.7 & 49.5 & 52.6 & & \\
\hline & 2 nd grade & count & 18 & 15 & 28 & 36 & 27 & 4 & 0.434 \\
\hline & & expected count & 20.5 & 15.3 & 27.3 & 29.5 & 31.4 & & \\
\hline 12. & 1st grade & count & 89 & 43 & 34 & 18 & 23 & & \\
\hline & & expected count & 83.2 & 50.0 & 34.4 & 19.4 & 20.0 & 1 & \\
\hline & 2nd grade & count & 44 & 37 & 21 & 13 & 9 & 4 & 0.200 \\
\hline & & expected count & 49.8 & 30.0 & 20.6 & 11.6 & 12.0 & & \\
\hline
\end{tabular}

df: degrees of freedom. ${ }^{*} \mathrm{p}<0.05$. 
tiveness of visual methods compared to auditory and other methods in the teaching-learning process reveals the importance of practical lectures in learning Anatomy. ${ }^{[23]}$

In the present study, it was observed that medical students did not look positively towards online education. It is understood that the students were not satisfied with the anatomy lectures they took during this period. Most of the students are opposed to online anatomy practical lectures. As a result, the students think that it is more beneficial to learn the practical lectures interactively in the laboratory environment by touching the visual anatomical models.

It has been observed that univesity students prefer formal education to online education in different studies conducted in Turkey. In a study in which student feedbacks about online education during the pandemic period were obtained, $90.3 \%$ of the physical therapy and rehabilitation students participating in the survey stated that they preferred face-to-face education and only $9.7 \%$ stated that they preferred online education. ${ }^{[20]}$ In another study that online education methods and students' feedback were evaluated, most of the students $(84.4 \%)$ stated that online education was not as effective as face-to-face education. As a result, face-to-face courses in the classroom environment continue to be considered as valuable by students. ${ }^{[24]}$ In some studies conducted with nursing students prior to the Covid-19 pandemic, no significant difference was reported between online education and face-to-face education in terms of student satisfaction. ${ }^{[25,26]}$

In a study conducted in Turkey that evaluated postgraduate anatomy education during pandemic period, it was reported that the students favored theoretical education to be partly online however, preferred face-to-face education in practical lectures. This study, which evaluates graduate students' view of anatomy education, has similar results with our study. ${ }^{[2]}$ In another study evaluating physiotherapy students' attitudes towards online anatomy education, the is view of the studens were nearly almost similar with our study. When they were asked whether they wanted to follow to the Anatomy course online or not, most of the students answered as "completely disagree". In addition to this, less than $20 \%$ of the students found theorotical and practical online anatomy lectures as effective as face to face education. ${ }^{[28]}$

There are also studies showing the positive aspects of distance education. For example; in a study conducted on dentistry students during the Covid-19 pandemic, it was shown that distance education promotes self-learning independence and improves their ability to use online resources $^{[29]}$ and supports students' critical thinking and high-level learning. ${ }^{[2]}$ In a study conducted in the pharmacy faculty, students reported that online education is valuable. ${ }^{[30]}$ In some studies conducted on nursing students, it has been shown that students are more satisfied with online education than face-to-face learning. ${ }^{[31-33]}$

\section{Conclusion}

The limited availability of cadaver, time, and resources has encouraged anatomists to adopt new technologies such as online education for years. Sometimes constraints can turn into opportunities to develop innovations and creative solutions. The Covid-19 crisis could bring anatomists together to apply alternative forms of education to improve anatomy education in medical schools. ${ }^{[34]}$ In this respect, we think that our study will lead the way to create awareness for the development of the online anatomy education model and to conduct similar studies in other branches. Further studies should be conducted to assess the effectiveness of various online education strategies for better anatomy education. The effects of Covid-19 may forever change future physicians' medical education.

\section{Conflict of Interest}

The authors declare that there is no conflict of interest.

\section{Author Contributions}

All authors equally contributed to concept, design and writing manuscript.

\section{Ethics Approval}

This study was approved by Afyonkarahisar Health Sciences University Clinical Research Ethics Committee with the protocol number 2011-KAEK-2 meeting number 2020-10.

\section{Funding}

The authors received no financial support for this study.

\section{References}

1. World Health Organization. Novel coronavirus (2019-nCoV): situation report 1. 21 January 2020. [Internet] [Retrieved on March 30, 2020]. Available from: https://www.who.int/docs/default-source/ coronaviruse/situation-reports/20200121-sitrep-1-2019-ncov.pdf? sfvrsn=20a99c10_4

2. Republic of Turkey Ministry of Health. Covid-19 information page 30 March 2020. [Internet] [Retrieved on March 30, 2020] Available from: https://covid19bilgi.saglik.gov.tr/tr/gunluk-vaka.html.

3. Turkish Higher Education Council. Press Release. 18 March 2020. [Internet] [Retrieved on March 30, 2020]. Available from: https://www.yok.gov.tr/Sayfalar/Haberler/2020/universitelerdeuygulanacak-uzaktan-egitime-iliskin-aciklama.aspx

4. Recen D, Başer A, Yıldırım B. Covid-19 döneminde diş hekimliği ve tup eğitiminde uzaktan öğrenme. Izmir Democracy University International Dentistry and Health Congress Full Paper Proceedings Book 2000;312-6. 
5. Al-Balas M, Al-Balas HI, Jaber HM, Obeidat K, Al-Balas H, Aborajooh EA, Al-Taher R, Al-Balas B. Distance learning in clinical medical education amid COVID-19 pandemic in Jordan: current situation, challenges, and perspectives. BMC Med Educ 2020;20:341.

6. Moore JL, Dickson-Deane C, Galyen K. e-Learning, online learning, and distance learning environments: are they the same? The Internet and Higher Education 2011;14:129-35.

7. Telli S, Altun D. The coronavirus and the rising of online education. Journal of University Research 2020;3:25-34.

8. Yamamoto GT, Özgeldi M, Altun D. Instructional developments and progress for open and equal access for learning. Open and Equal Access for Learning in School Management 2018;117-143.

9. Hall S, Border S. Online neuroanatomy education and its role during the coronavirus disease 2019 (Covid-19) lockdown. World Neurosurgery 2020;139:628.

10. Alonso F, López G, Manrique D, Viñes JM. An instructional model for web-based e-learning education with a blended learning process approach. British Journal of Educational Technology 2005;36:21735 .

11. Skochelak SE, Stack SJ. Creating the medicalschools of the future. Acad Med 2017;92:16-9.

12. Zihni NB, Turhan K, Can MA. Observing human-computer interaction at long-distance learning site prepared for medical education. Journal of Engineering and Natural Sciences 2013;5:15-24.

13. Saverino D. Teaching anatomy at the time of Covid-19. Clin Anat Epub 2020 April 29. DOI 10.1002/ca.23616.

14. Triepels CPR, Koppes DM, Van Kuijk SMJ, Popeijus HE, Lamers WH, van Gorp T, et al. Medical students' perspective on training in anatomy. Ann Anat 2018;217:60-5.

15. Linn RL, Miller MD. Measurement and assessment in teaching. 11th ed. Cranbury (NJ): Pearson Education; 2012. 576 p.

16. Keskin M, Özer Kaya D. Evaluation of students' feedbacks on webbased distance education in the Covid-19 process. İzmir Kâtip Çelebi University Faculty of Health Sciences Journal 2020;5:59-67.

17. Yammine K, Violato C. The effectiveness of physical models in teaching anatomy: A meta-analysis of comparative studies. Adv Health Sci Educ Theory Pract 2016;21:883-95.

18. Pather N. Teaching anatomy: prosection and dissection. In: Chan LK, Pawlina W, editors. Teaching anatomy: a practical guide. 1st Ed. New York (NY): Springer International Publishing; 2015. p. 213-221.

19. Dogan HGB. Distance education and lifelong learning. [Internet] [Retrieved on March 30, 2020]. Available from: http://www.egitimde teknoloji.com/uzaktan-egitim-yasam-boyu-ogrenme-nedir/

20. Yilmaz N. Investigation of students' attitudes towards applied distance education in the covid-19 pandemic process in higher educa- tion institutions: example of physiotherapy and rehabilitation department. Necmettin Erbakan University Faculty of Health Sciences Journal 2020;3:15-20.

21. Dolmands DHJM, Gijselaers WH, Moust JHC, de Grave WS, Wolfhagen IHAP, van der Vleuten CPM. Trends in research on the tutor in problem-based learning: conclusions and implications for educational practice and research. Med Teach 2002;24:173-80.

22. Bates AW, Poole G. Effective teaching with technology in higher education. San Francisco (CA): John Wiley \& Sons; 2003. 319 p.

23. Carmichael SW, Pawlina W. Animated powerpoint as a tool to teach anatomy. Anat Rec 2000;261:83-88.

24. Ricchardson J C, Maeda Y, Lv J, Caskurlu S. Social presence in relation to students' satisfaction and learning in the online environment. Computers in Human Behavior 2017;71:402-17.

25. Jang KS, Hwang SY, Park SJ, Kim YM, Kim MJ. Effects of a Webbased teaching method on undergraduate nursing students' learning of electrocardiography. J Nurs Educ 2005;44:35-9.

26. Gega L, Norman IJ, Marks IM. Computer-aided vs. tutor-delivered teaching of exposure therapy for phobia/panic: randomized controlled trial with pre-registration nursing students. Int J Nurs Stud 2007;44:397-405.

27. Temizsoy Korkmaz F, Gürses İ. Initial effects of Covid-19 pandemic on graduate anatomy education in Turkey. Anatomy 2020;14:12333.

28. Turhan B, Yakut Y. The opinions of physiotherapy students on online anatomy education during Covid-19 pandemic. Anatomy 2020;14: $134-8$.

29. Prati C, Pelliccioni GA, Sambri V, Chersoni S, Gandolfi MG. Covid-19: its impact on dental schools in Italy, clinical problems in endodontic therapy and general considerations. Int Endod J 2020; 53:723-5.

30. Cain J, Scott DR, Akers P. Pharmacy students' Facebook activity and opinions regarding accountability and e-professionalism. Am J Pharm Educ 2009;73:104.

31. Gerdprasert S, Pruksacheva T, Panijpan B, Ruenwongsa P. Development of a web-based learning medium on mechanism of labour for nursing students. Nurse Educ Today 2010;30:464-9.

32. Kaveevivitchai C, Chuengkriankrai B, Luecha Y, Thanooruk R, Panijpan B, Ruenwongsa P. Enhancing nursing students' skills in vital signs assessment by using multimedia computer-assisted learning with integrated content of anatomy and physiology. Nurse Educ Today 2009;29:65-72.

33. McMullan M, Jones R, Lea S. The effect of an interactive e-drug calculations package on nursing students' drug calculation ability and self-efficacy. Int J Med Inform 2011;80:421-30.

34. Ghosh SK. Cadaveric dissection as an educational tool for anatomical sciences in the 21st century. Anat Sci Educ 2017;10:286-99.
ORCID ID:

O. Turamanlar 0000-0002-0785-483X; H. Güzel 0000-0001-7692-8890
Correspondence to: Hilal Güzel, PhD

Department of Anatomy, Faculty of Medicine,

Afyonkarahisar Health Sciences University, Afyonkarahisar, Turkey

Phone: +902722463301

e-mail: hilalgzl@hotmail.com

Conflict of interest statement: No conflicts declared.

This is an open access article distributed under the terms of the Creative Commons Attribution-NonCommercial-NoDerivs 4.0 Unported (CC BY-NCND4.0) Licence (http://creativecommons.org/licenses/by-nc-nd/4.0/) which permits unrestricted noncommercial use, distribution, and reproduction in any medium, provided the original work is properly cited. How to cite this article: Turamanlar O, Güzel H. The view of medical students on the anatomy course given by distance education during Covid-19 pandemic. Anatomy 2020;14(3):202-209. 


\section{Appendix 1}

The view of medical students on the anatomy courses given by distance education during the covid-19.

\section{Questionnaire}

Dear Participant,

As of March 16, 2020, due to the measures taken due to the Covid-19 virus pandemic across the country, classroom (face-to-face) learning at universities was stopped and distance learning was started. Our aim in this study is to understand the problems faced by the medical students while taking anatomy courses, as well as to determine the possible benefits of distance learning through a web-based questionnaire system, and to compare it with formal classroom learning. Therefore, your partic ipation in the study is valuable in order to contribute to the development of anatomy education and determine the distance learning model from the students' perspective.

You are asked to mark the degree to which you adopt each of the statements below. It should be noted that there are no right or wrong answers for your answers. It is important to state what you think about the subject and what your approach is. For this reason, your answers are required to be sincere. The information you provide will be protected and evaluated according to confidentiality principles. The data obtained from this study, for which your personal information is not requested, will only be used in scientific environments.

It is not mandatory for you to participate in this survey study. Your willingness to participate is essential. There is no risk that you will be exposed to any corporate or personal criticism, negative perception or situations that may affect your education opportunities because of your participation in the study. Please do not hesitate to contact us for more detailed information and any questions you may have. Thank you for your interest and participation.

Assoc. Prof. Dr. Ozan Turamanlar: ozanturamanlar@hotmail.com

Res. Asst. Dr. Hilal Güzel: hilalgz|@hotmail.com

\section{Student Information Form}

$\begin{array}{lll}\text { Gender: } & \square \text { Female } & \square \text { Male } \\ \text { Class: } & \square 1 & \square 2\end{array}$

I have listened to anatomy theoretical lectures taught by distance learning $\quad \square \quad$ Yes $\quad \square$ No

I have listened to anatomy practical lectures taught by distance learning $\quad \square$ Yes $\quad \square$ No

\section{Web-Based Student Feedback Questionnaire}

1. I think that the online anatomy theoretical lectures I have taken during the pandemic process will / will be sufficient for my medical profession.

\begin{tabular}{|c|c|c|c|c|}
\hline Completely disagree & Disagree & No idea & Agree & Completely agree \\
\hline \multicolumn{5}{|c|}{ I I think that the onilne anatomy practical lectures I have taken during the pandemic process will / will be sufficient for my medical profession. } \\
\hline Completely disagree & Disagree & No idea & Agree & Completely agree \\
\hline Completely disagree & Disagree & No idea & Agree & Completely agree \\
\hline Completely disagree & Disagree & No idea & Agree & Completely agree \\
\hline
\end{tabular}

5. I think that distance learning is more beneficial in terms of teaching than the theoretical lesson given in crowded classroom environment.

\begin{tabular}{|c|c|c|c|c|}
\hline Completely disagree & Disagree & No idea & Agree \\
\hline
\end{tabular}

6. I think that the anatomy theoretical lectures given by distance learning are more efficient than the classroom lectures in terms of the opportunity to listen to the lecture again.

\begin{tabular}{|l|l|l|l|l|}
\hline Completely disagree & Disagree & No idea & Agree \\
\hline
\end{tabular}

7. I think it is more appropriate to teach the anatomy theoretical lectures in a student-centered interactive manner in the classroom atmosphere.

\begin{tabular}{|c|c|c|c|c|}
\hline Completely disagree & Disagree & No idea & Agree \\
\hline
\end{tabular}

8. I think it is not appropriate to learn anatomy practical lectures without touching the cadaver and the anatomical model.

\begin{tabular}{|c|c|c|c|c|}
\hline Completely disagree & Disagree & No idea & Agree \\
\hline
\end{tabular}

9. In terms of anatomy practical lectures, I think it is more efficient to work interactively with assistants and friends in the laboratory environment.
Completely disagree
Disagree
No idea
Agree
Completely agree

10. I think that the visual presentation of the anatomy practical lecture contents in the form of videos and the chance to watch it again, make it easier for me to learn in the distance learning process.

\begin{tabular}{|c|c|c|c|c|}
\hline Completely disagree & Disagree & No idea & Agree Completely agree \\
\hline
\end{tabular}

11. I think that the anatomy theoretical lectures to be given in medical schools in the following years should be online and the practical lectures should be in the laboratory environment.

\begin{tabular}{|c|c|c|c|c|}
\hline Completely disagree & Disagree & No idea & Agree & Completely agree \\
\hline \multicolumn{5}{|c|}{ 2. As a medical student, I think that the courses (especially the anatomy course due to the high course hours) should be given both theoretically and practically in } \\
\hline Completely disagree & Disagree & No idea & Agree & Completely agree \\
\hline
\end{tabular}

